\title{
JUSTINE DOCKX, «Conteurs, soufflez!». Variations entre écoute et lecture silencieuse, «Mosaïque»
}

\section{Maria Colombo Timelli}

\section{Q OpenEdition}

\section{Journals}

\section{Édition électronique}

URL : https://journals.openedition.org/studifrancesi/11320

DOI : $10.4000 /$ studifrancesi. 11320

ISSN : 2427-5856

\section{Éditeur}

Rosenberg \& Sellier

\section{Édition imprimée}

Date de publication : 1 avril 2018

Pagination : 115

ISSN : 0039-2944

\section{Référence électronique}

Maria Colombo Timelli, « Justine dockx, «Conteurs, soufflez!». Variations entre écoute et lecture silencieuse, «Mosaïque» », Studi Francesi [En ligne], 184 (LXII | I) | 2018, mis en ligne le 29 juin 2018, consulté le 15 novembre 2021. URL : http://journals.openedition.org/studifrancesi/11320 ; DOI : https://doi.org/ 10.4000/studifrancesi. 11320

Ce document a été généré automatiquement le 15 novembre 2021.

\section{(c) (i) (9) $\Theta$}

Studi Francesi è distribuita con Licenza Creative Commons Attribuzione - Non commerciale - Non opere derivate 4.0 Internazionale. 


\title{
JUSTINE DOCKX, «Conteurs, soufflez!». Variations entre écoute et lecture silencieuse, «Mosaïque»
}

\author{
Maria Colombo Timelli
}

\section{RÉFÉRENCE}

JUSTINE DOCKX, «Conteurs, soufflez!». Variations entre écoute et lecture silencieuse, «Mosaïque», Revue de jeunes chercheurs en SHS, Lille Nord-de-France - Belgique, 14, décembre 2014 (mis en ligne avril 2017), pp. 36-48.

1 Justine Dockx, dont la thèse en cours fournira l'édition de la seconde partie d'Anseÿs de Gascogne, essaie de retrouver dans le manuscrit copié par David Aubert pour Philippe le Bon (Bruxelles, KBR, ms 8) tant les traces d'une «oralité» qui demeurerait vivante au $\mathrm{XV}^{\mathrm{e}}$ siècle que le passage à la lecture silencieuse dont témoignerait la mise en place d'une ponctuation moderne. Il faudra souligner cependant que les indices d'une «mise en voix» repérées dans le texte pourraient être le fait de l'auteur de cette mise en prose, alors que les barres et autres signes de ponctuation ne peuvent qu'être attribués au copiste. Questions des plus épineuses dans la mesure où, d'une part, le rôle de David Aubert (auteur ou copiste?) pour les Histoires de Charles Martel n'est pas défini; d'autre part, même si on ne lui attribuait que la deuxième fonction, on sait qu'il ne s'est jamais privé d'intervenir - et lourdement - dans les textes qu'il transcrivait pour ses mécènes. Parmi les preuves d'une lecture oralisée du texte, J.D. dénombre tant les interventions du narrateur (du type «Que vous feroit l'en long compte?», ou «L'istoire raconte que...») que le recours à certains verbes («dist l'istoire», «comme ouy avez»...), ainsi que les précisions introduites et plusieurs fois répétées pour rappeler la parenté de certains personnages, ou encore les reprises, en début de chapitre, de segments de phrases présents dans le chapitre précédent. Parmi les éléments de «ponctuation», J.D. attribue un rôle important à la subordination (à ses yeux, les nombreuses phrases subordonnées 
contribuent à «cré[er] le rythme» du texte, p. 43), à côté des signes proprement dits (barre oblique et petits carrés); ces derniers mériteraient une étude plus poussée, dans la mesure où ils semblent indiquer en particulier le début des répliques au discours direct et, parfois, le retour à la narration.

2 Article intéressant pour les spécialistes de David Aubert, personnage qui fait actuellement l'objet d'un intérêt renouvelé (on rappellera qu'une session du Colloque «Raconter en prose», Turin, 2014, lui a été consacrée: les Actes sont actuellement sous presse aux Classiques Garnier; d'autres éditions de textes écrits ou copiés par lui sont aussi en cours), mais qui présente certaines faiblesses, notamment l'absence d'une bibliographie de référence pour les sujets (importants) abordés, que ce soit l'histoire de la transmission des textes - entre lecture oralisée et lecture silencieuse -, l'histoire de la ponctuation et de la syntaxe, ou encore David Aubert lui-même. 